\title{
Quality assessment of intraoperative frozen sections: An analysis of 261 consecutive cases in a resource limited area: Morocco
}

\author{
Laila Chbani", Sekal Mohamed, Tawfik Harmouch, Hinde El Fatemi, Afaf Amarti \\ Department of Pathology, Hassan II Teaching Hospital, Fez, Morocco; ${ }^{*}$ Corresponding Author: chbanil@yahoo.fr
}

Received 24 March 2012; revised 19 April 2012; accepted 29 April 2012

\begin{abstract}
Purpose: To evaluate the accuracy and limits of a frozen section analysis in our department in order to develop a quality control. Materials and methods: all frozen sections reported at our department between $1^{\text {st }}$ January 2010 and $31^{\text {st }}$ December 2010, have been retrospectively evaluated. The frozen section results were compared to permanent paraffin section results. Results: Frozen sections and final diagnosis agreed in $95 \%$ and disagreed in $5 \%$ (13 cases), $6.6 \%$ of the cases were deferred (17 cases). The most common pathological processes encountered were presenceltyping of neoplasm (85.4\%) and assessment of surgical margins (7.3\%). Conclusion: The accuracy of frozen sections diagnosis at our department can be interpreted as comparable with the most international quality control series and is valuable to assist surgeons in their decision.
\end{abstract}

Keywords: Frozen Sections; Quality Control; Discrepancies; Accuracy

\section{INTRODUCTION}

The frozen section (FS) is a pathological laboratory procedure in which intraoperative and immediate down results can guide the surgical suites. The result of the frozen section should be confirmed after fixation and paraffin embedding of the fragment examined intraoperatively [1].

The correlation of intra-operative frozen section diagnosis with the final histological diagnosis on permanent sections should form an integral part of quality assurance activities in pathology department.

Frozen section has several indications as to identify the nature of the lesion and to assessment the quality of surgical margins in malignant tumours [2].
In the current study, we investigate the diagnostic accuracy of frozen section and the factors affecting the FS results.

\section{MATERIAL AND METHODS}

We retrospectively reviewed 261 cases of FS performed in our laboratory over a period of 1 year (1st January 2010 and December 31, 2010). The indication for examination was fixed in advance by the surgeon.

Once in the laboratory, the sample is immediately frozen in cryostat $-19^{\circ} \mathrm{C}$, cut with a thickness of $5 \mu \mathrm{m}$ and then stained with Hematoxylin \& Eosin (HE) for 2 to 3 minutes. Once the answer provided, the fragments will be examined and unexamined thawed and then fixed in $10 \%$ formalin, embedded in paraffin and stained with HES.

Data has been obtained on the basis of patient files pathology reports.

For each frozen section, we considered the siege of sampling and the indication of the examination.

The parameters collected were seized on Microsoft Office Excel 2003. Statistical analysis was performed using the Epi Info version 3.4.

\section{RESULTS}

The total number of samples received in our department during the study period was approximately 14000 . A total of 261 specimens were received for FS which represents $1.66 \%$ of our activity.

Permanent section diagnosis of all 261 specimens revealed 95\% (248 cases) neoplastic and 5\% (13 cases) non neoplastic lesions. In neoplastic group, $65 \%$ of tumours were benign, 35\% malignant. From the point of tissue origin, most of specimens were from central nervous system ( 82 cases) and breast (54 cases) (Table 1).

In our study, 17 cases were deferred to permanent sections $(6.6 \%)$. Of the remaining 243 cases, 13 cases were discordant (5\%) while 231 cases were concordant (95\%) (Figure 1). 
The most common indication of FS were verification and classification of tumors in $85.4 \%$ (223 cases) and verification of quality of surgical excision in $7.3 \%$ (19 cases) (Table 2).

Of the 13 discordant cases, there were eight false negative (diagnosis not made in the FS) and five false positive (diagnosis of malignancy proposed by FS, not confirmed by the final histopathological diagnosis on tissue was present only on cuts controls and in five cases $(38.5 \%)$ this was a misinterpretation of the pathologist in

Table 1. Number and percent of concordant, discordant and deferral cases.

\begin{tabular}{|c|c|c|c|c|}
\hline Site & $\begin{array}{l}\text { Number } \\
\text { of cases }\end{array}$ & $\begin{array}{c}\text { Concordant } \\
\text { cases }\end{array}$ & $\begin{array}{c}\text { Discordant } \\
\text { cases }\end{array}$ & $\begin{array}{c}\text { Deferral } \\
\text { cases }\end{array}$ \\
\hline $\begin{array}{l}\text { Central Nervous } \\
\text { System }\end{array}$ & 82 & 72 & 04 & 06 \\
\hline Breast & 54 & 36 & 02 & 03 \\
\hline Nodes & 25 & 25 & 0 & 0 \\
\hline Ovary & 17 & 14 & 01 & 02 \\
\hline Thyroid & 13 & 11 & 02 & 0 \\
\hline $\begin{array}{l}\text { Gastrointestinal } \\
\text { tract }\end{array}$ & 05 & 05 & 0 & 0 \\
\hline Skin & 12 & 10 & 01 & 01 \\
\hline Peritoneum & 09 & 09 & 0 & 0 \\
\hline $\begin{array}{l}\text { Liver and biliary } \\
\text { tract }\end{array}$ & 05 & 3 & 2 & 0 \\
\hline Other & 38 & 34 & 3 & 1 \\
\hline Total & 261 & $231(88.5 \%)$ & $13(4.9 \%)$ & $17(6.6 \%)$ \\
\hline
\end{tabular}

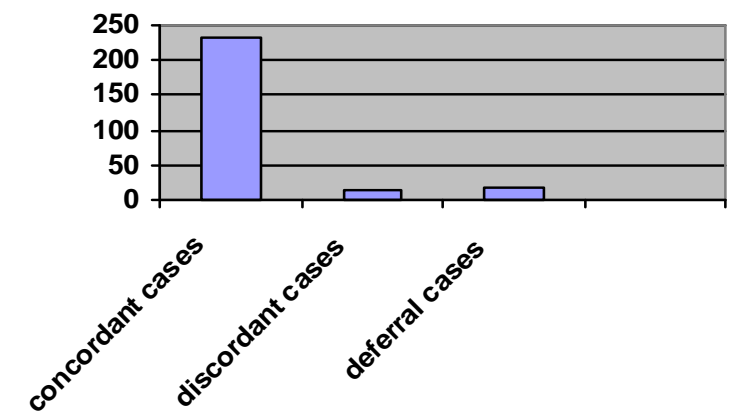

Figure 1. Accuracy of frozen section in our department.

Table 2. Indications of frozen sections.

\begin{tabular}{lc}
\hline Indications of FS & Frequency (\%) \\
\hline Categorization of neoplasm & 85.4 \\
Presence or absence of ganglion cells & 4.3 \\
Assessment of tumor margins & 7.3 \\
Other & 3 \\
\hline
\end{tabular}

the grading of tumors of central nervous system. It should be noted that in 10 cases $(77 \%)$ the diagnostic discordance between the results of frozen section and the final result had no consequences for the patient. The implication for the 3 other cases had reoperation.

The deferral cases were those that subtyping of the lesion was no possible in FS but there was not any problem to diagnose the samples as benign or malignant.

The sensitivity of FS as a diagnostic test was $95.02 \%$ and the positive predictive value was $98.02 \%$.

\section{DISCUSSION}

In this work, we retrospectively studied the results of FS made in the Department of Pathology of Hassan II Teaching Hospital for a year.

Moreover, the evaluation of FS is required to identify any problems in order to correct them. Finally, we felt it important to initiate this process in our department, which can then be extended to other areas of laboratory activity. Our results (5\% discordant diagnoses) are the same as the main general series published [3-5]. Indeed, we find in the literature data [3-8] a discordant diagnosis rates ranging from $1.7 \%$ to $4.9 \%$ (average $3.2 \%$ ) (Table 3 ).

As in these series, we observed a low rate of false positive diagnoses among these discordant (five false positive diagnoses of the 13 discordant, or $1.9 \%$ of all FS).

The discordance between the diagnostic results of the FS and the final result was rarely due to a misinterpretation of the pathologist (5 of 13 cases). In other cases, it was sampling problems, the diagnostic tissue being present only on cuts controls $(61.5 \%)$.

These data are consistent with published series where we also note that false positives are usually due to errors of interpretation, while false negatives are often due to sampling problems [9-13]. Increase the number of histological sections or the number of samples by FS might improve diagnostic performance, but at the expense of the speed of the FS. Moreover, these practices can also

Table 3. Literature overview on frozen section accuracy.

\begin{tabular}{|c|c|c|c|c|}
\hline Authors & $\begin{array}{l}\text { Study } \\
\text { period }\end{array}$ & $\begin{array}{l}\text { Number } \\
\text { of cases }\end{array}$ & $\begin{array}{c}\text { Concordant } \\
\text { rate } \%\end{array}$ & $\begin{array}{l}\text { Discordant } \\
\text { rate } \%\end{array}$ \\
\hline Zubair et al. [6] & 1 year & 356 & 97.08 & 2.9 \\
\hline Wendum et al. [7] & 1 year & 847 & 98.2 & 1.7 \\
\hline Winther et al. [3] & 1 year & 4785 & 95.1 & 4.9 \\
\hline Geramizadeh et al. [5] & 4 years & 759 & 97.7 & 3.3 \\
\hline Abbasi et al. [4] & 7 years & 200 & 96.5 & 4.5 \\
\hline Ferreiro et al. [8] & 1 year & 24880 & 97.8 & 2.2 \\
\hline $\begin{array}{l}\text { Chbani et al. } \\
\text { (current study) }\end{array}$ & 1 year & 261 & 95 & 5 \\
\hline
\end{tabular}


interfere with the quality of the final diagnosis as making several cutting planes can cause depletion of the block and thus prevent the production of cut controls. Also, make multiple samples from a specimen may hinder its review and sampling after the FS and therefore interfere with the quality of the final diagnosis.

In $6.6 \%$ of FS, the response was delayed. This frequency is relatively high when compared with the results published in the literature (deferred diagnoses ranging from 0.04 to $6.7 \%$ [12,14], average $2.1 \%$ ). Only two series have rates comparable to ours $[12,15]$.

This high rate of deferred diagnoses is explained by the large share of FS on the central nervous system (CNS) tumors in our series. Indeed, the CNS was the most frequently site examined in frozen section in our laboratory (Table 1) and these tests represented $31.4 \%$ of all FS.

This high rate of delayed diagnosis in CNS neoplasm is found in some studies [16].

Typing and grading error was very frequent in neurosurgical biopsies. Freezing artifact, obscuring cytological detail and heterogeneous behavior of gliomas are the causes for deferred diagnosis. Many studies have mentioned about taking multiple samples from different areas of a lesion and using smear/squash cytological technique along with the FS to reduce the error [17].

\section{CONCLUSION}

Our study shows that FS is fast and reliable. Discordant diagnoses are usually false negative, usually due to sampling problems. Moreover, a high rate of deferred diagnoses is observed in CNS neoplasm, but does not call into question the utility of FS in this type of pathology. The communication with neurosurgeons is recommended such as pathologist experience. The causes of discordance between frozen section analysis and final histology are varied, complex and sometimes difficult to interpret.

\section{REFERENCES}

[1] Saint-André, J.P., Donzel, J.P., Anger, E., Chatelet, F., Cochand-Priollet, B., De Graeve, P., et al. (1998) Recommandations de bonnes pratiques en anatomie et cytologie pathologiques. Document préparé par l'Association Française d'Asuurance Qualité en Anatomie et Cytologie Pathologiques (AFAQAP). Comission No 4: Organisation et fonctionnement des structures. Annales de Pathologie, 18, 227236.

[2] Özdamar, S., Bahadir, B., Ekem, T., Kertis, G., Gün, B., Numanoðlu, G., et al. (2006) Frozen section experience with emphasis on reasons for discordance. Turkish Journal of Cancer, 4, 157-161.

[3] Winther, C. and Græm, N. (2011) Accuracy of frozen section diagnosis: A retrospective analysis of 4785 cases. Acta Pathologica, Microbiologica et Immunologica Scan- dinavica, 119, 259-262.

[4] Geramizadeh, B., Larijani, T.R., Owji, S.M., Attaran, S.Y., Torabinejad, S., Aslani, F.S., et al. (2010) Accuracy of intra-operative frozen section consultation in south of Iran during four years. Indian Journal of Pathology and Microbiology, 3, 414-417. doi:10.4103/0377-4929.68250

[5] Abbasi, F., Yekta, Z. and Aryan, A. (2012) Accuracy of Frozen sections. Iranian Journal of Pathology, 1, 3-8.

[6] Zubair, A., Barakzai, M.A., Idrees, R. and Bhurgri, Y. (2008) Correlation of intra-operative frozen section consultation with the final diagnosis at a referral center in Karachi, Pakistan. Indian Journal of Pathology and Microbiology, 51, 469-473. doi:10.4103/0377-4929.43733

[7] Wendum, D. and Fléjou, J.F. (2003) Evaluation qualitative des examens extemporanés dans un service hospitalouniversitaire: Analyse de 847 examens consécutifs. Annales de Pathologie, 23, 393-399.

[8] Ferreiro, J.A., Myers, J.L. and Bostwick, D.J. (1995) Accuracy of frozen section diagnosis in surgical pathology: Review of a 1-year experience with 24,880 cases at Mayo Clinic Rochester. Mayo Clinic Proceedings, 12, 1137-1141. doi:10.4065/70.12.1137

[9] Lerman, R.I. and Pitcock, J.A. (1972) Frozen section experience in 3.249 specimens. Surgery Gynecology \& Obstetrics, 135, 930-932.

[10] Saltzstein, S.L. and Nahum, A.M. (1973) Frozen section diagnosis: Accuracy and errors; uses and abuses. Laryngoscope, 83, 1128-1143. doi:10.1288/00005537-197307000-00017

[11] Prey, M.U., Vitale, T. and Martin, S.A. (1989) Guidelines for practical utilization of intraoperative frozen sections. Archives of Surgery, 124, 331-335. doi:10.1001/archsurg.1989.01410030081013

[12] Torp, S.H. and Skjorten, F.J. (1990) The reliability of frozen section diagnosis. Acta Chirurgica Scandinavica, 156, 127-130.

[13] Howanitz, P.J., Hoffman, G.G. and Zarbo, R.J. (1990) The accuracy of frozen-section diagnoses in 34 hospitals. Archives of Pathology \& Laboratory Medicine, 114, 355359.

[14] Bredahl, E. and Simonsen, J. (1970) Routine performance of intra-operative frozen section microscopy, with particular reference to diagnostic accuracy. Acta Pathologica et Microbiologica Immunologica Scandinavica Supplementum, 212, 104.

[15] Oneson, R.H., Minke, J.A. and Silverberg, S.G. (1989) Intraoperative pathologic consultation. An audit of 1000 recent consecutive cases. The American Journal of Surgical Pathology, 13, 237-243. doi:10.1097/00000478-198903000-00009

[16] Shrestha, S., Lee, M.C., Dhakal, H., Pun, C.B., Pradhan, M., Shrestha, S., Basyal, R. and Pathak, T. (2009) Comparative Study of frozen section diagnoses with histopathology. Post Graduate Medical of NAMS, 9, 1-5.

[17] Folkerth, R.D. (1994) Smears and drozen sections in the intraoperative diagnosis of central nervous system lesions. Neuropathology, 5, 1-18. 